\title{
Halting angiogenesis by non-viral somatic gene therapy alleviates psoriasis and murine psoriasiform skin lesions
}

\author{
John R. Zibert, ${ }^{1}$ Katrin Wallbrecht, ${ }^{2,3}$ Margarete Schön,, ${ }^{2,4}$ Lluis M. Mir,,5,6 Grete K. Jacobsen, ${ }^{7}$ \\ Veronique Trochon-Joseph, ${ }^{8}$ Céline Bouquet, ${ }^{8}$ Louise S. Villadsen, ${ }^{1}$ Ruggero Cadossi, ${ }^{9}$ \\ Lone Skov, ${ }^{1}$ and Michael P. Schön ${ }^{2,3}$
}

1Department of Dermato-Allergology, University of Copenhagen, Gentofte Hospital, Hellerup, Denmark. 2Department of Dermatology, Venereology, and Allergology, Georg August University, Göttingen, Germany. ${ }^{3}$ Rudolf Virchow Center, DFG Research Center for Experimental Biomedicine, Julius Maximilians University, Würzburg, Germany. ${ }^{4}$ Department of Cellular and Molecular Immunology, Georg August University, Göttingen, Germany. ${ }^{5}$ CNRS, UMR 8203, Institut Gustave-Roussy, Villejuif, France. 6University Paris-Sud, UMR 8203, Paris, France. ${ }^{7}$ Bartholin Institute, Rigshospitalet, Copenhagen, Denmark. ${ }^{8}$ BioAlliance Pharma SA, Paris, France. ${ }^{9}$ GEA S.p.A., Carpi, Italy.

\begin{abstract}
Dysregulated angiogenesis is a hallmark of chronic inflammatory diseases, including psoriasis, a common skin disorder that affects approximately $2 \%$ of the population. Studying both human psoriasis in 2 complementary xenotransplantation models and psoriasis-like skin lesions in transgenic mice with epidermal expression of human TGF- $\beta 1$, we have demonstrated that antiangiogenic non-viral somatic gene therapy reduces the cutaneous microvasculature and alleviates chronic inflammatory skin disorders. Transient muscular expression of the recombinant disintegrin domain (RDD) of metargidin (also known as ADAM-15) by in vivo electroporation reduced cutaneous angiogenesis and vascularization in all 3 models. As demonstrated using red fluorescent protein-coupled RDD, the treatment resulted in muscular expression of the gene product and its deposition within the cutaneous hyperangiogenic connective tissue. High-resolution ultrasound revealed reduced cutaneous blood flow in vivo after electroporation with RDD but not with control plasmids. In addition, angiogenesis- and inflammation-related molecular markers, keratinocyte proliferation, epidermal thickness, and clinical disease scores were downregulated in all models. Thus, non-viral antiangiogenic gene therapy can alleviate psoriasis and may do so in other angiogenesis-related inflammatory skin disorders.
\end{abstract}

\section{Introduction}

Dysregulated angiogenesis is emerging as a potential new target in inflammatory disorders, among which psoriasis, a common chronic inflammatory skin disorder that affects about $2 \%$ of the population, has attracted considerable interest among physicians and researchers alike (1-3). Due to its easy accessibility, psoriasis has increasingly become a model disorder in which to study the basic pathogenesis and therapy of chronic inflammatory diseases (4), genetic inheritance patterns $(5,6)$, complex cytokine networks (7), and central interactions of immune cells with epithelial tissues (8). In addition, several new therapies targeting immunological key mechanisms have been developed for psoriasis first (9-12).

Angiogenesis and morphological and functional alterations of microvessels are hallmark features of chronic inflammatory disorders, including psoriasis (13-15). It is thought that the proangiogenic microenvironment within psoriatic skin is induced by a $\mathrm{T}$ helper cell-initiated inflammatory response, which results in induction and activation of various proangiogenic factors, such as VEGF, HIF, TNF- $\alpha$, and CXCL-8 (16-19). The VEGF-related angiogenic milieu is also modulated by regulatory T cells (20) and influ-

Authorship note: John R. Zibert, Katrin Wallbrecht, Lone Skov, and Michael P. Schön contributed equally to this work

Conflict of interest: The CNRS, employer of Lluis M. Mir, holds patents on the Cliniporator, and Lluis M. Mir receives a fraction of the royalties. Veronique TrochonJoseph and Céline Bouquet are employed by BioAlliance, the manufacturer of the RDD construct. Ruggero Cadossi is a consultant for and stockholder of IGEA, the manufacturer of the Cliniporator, a device for in vivo electroporation. Citation for this article: J Clin Invest. 2011;121(1):410-421. doi:10.1172/JCI41295. ences key features of psoriasis, including epidermal hyperplasia (14). A single nucleotide polymorphism within the VEGF-encoding gene is associated with severe and early-onset forms of psoriasis (21). Of note, several modern therapies of psoriasis affect not only immunological processes but also reduce pathological vascular functions (22-25). Thus, it is reasonable to assume that direct targeting of angiogenesis will be an effective means to halt the psoriatic disease process, although direct evidence is still scant $(17,26,27)$.

Induced expression of adhesion molecules, such as integrins $\alpha_{5} \beta_{1}$ and $\alpha_{v} \beta_{3}$, on sprouting blood vessels is crucial for angiogenesis and serves as a key when using these receptors as therapeutic targets (28-30). Besides targeting components of the VEGF signaling pathway, adamalysin protein family members, also referred to as a disintegrin and metalloproteinases (ADAMs), are potential players interfering with angiogenesis. Metalloprotease-RGD-disintegrin (metargidin; also known as and referred to throughout as ADAM-15) is the only adamalysin known to bind integrins $\alpha_{5} \beta_{1}$ and $\alpha_{v} \beta_{3}(31,32)$. Indeed, a recombinant disintegrin fragment of ADAM-15 reduced angiogenesis and tumor growth (33). Therefore, in vivo expression of such factors is predicted to shift the proangiogenic milieu toward a more angiostatic situation, thus interfering with the pathogenesis of inflammatory disorders.

While it appears likely that in vivo expression of antiangiogenic factors would directly normalize the vascular dysregulation in chronic inflammation, gene therapeutic approaches have generally been hampered by the relatively low efficiency of naked DNA and safety concerns when viral vectors are used (34). In this situation, gene delivery by in vivo electroporation shows high transfection 


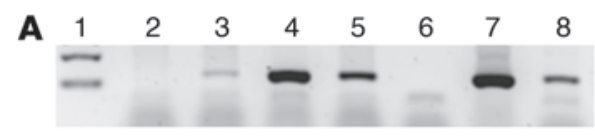

B
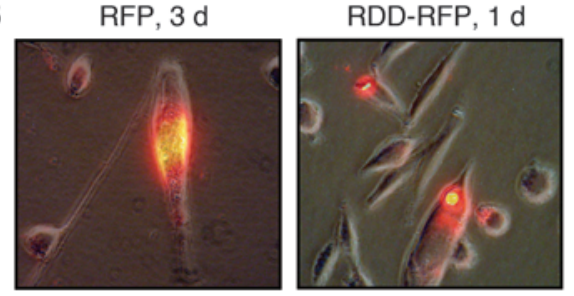

RDD-RFP, $3 d$

D
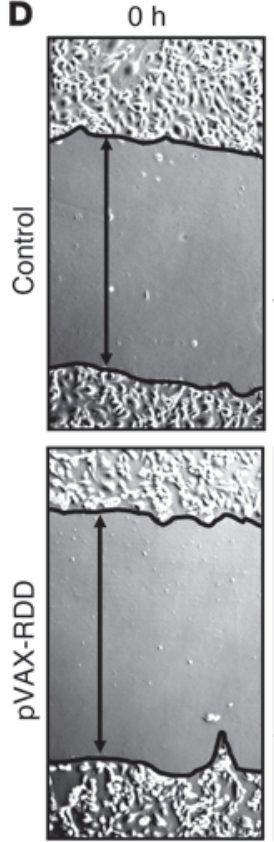

$6 \mathrm{~h}$

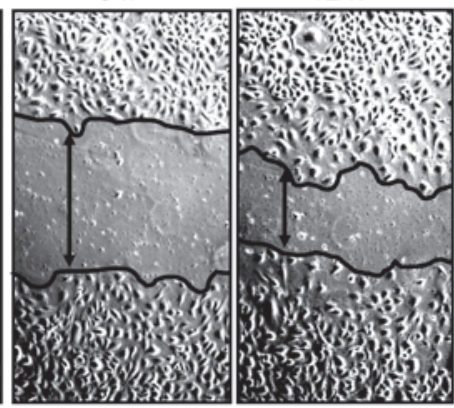

$24 \mathrm{~h}$
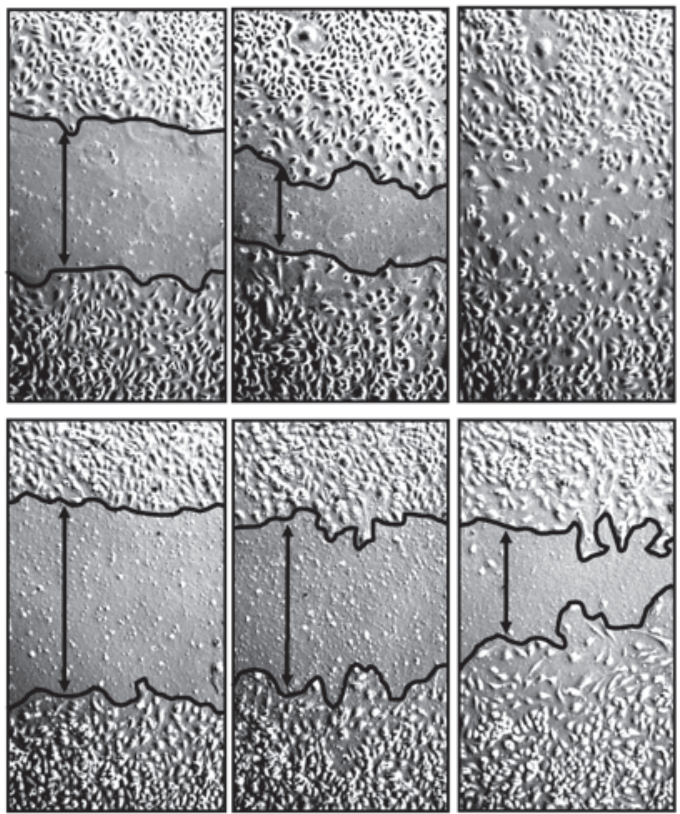

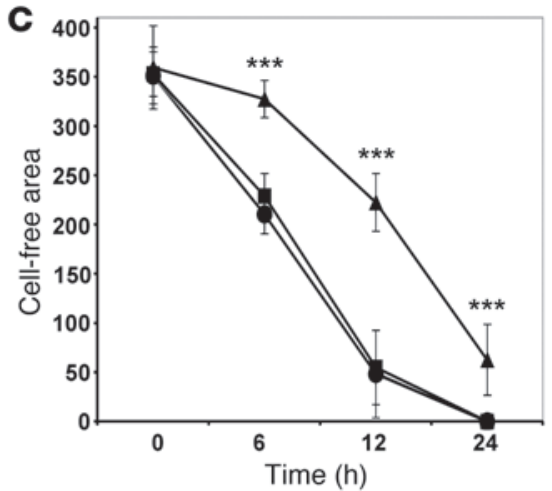

$29 \mathrm{~h}$
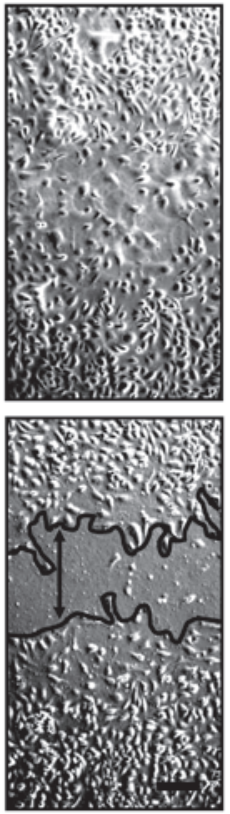

E
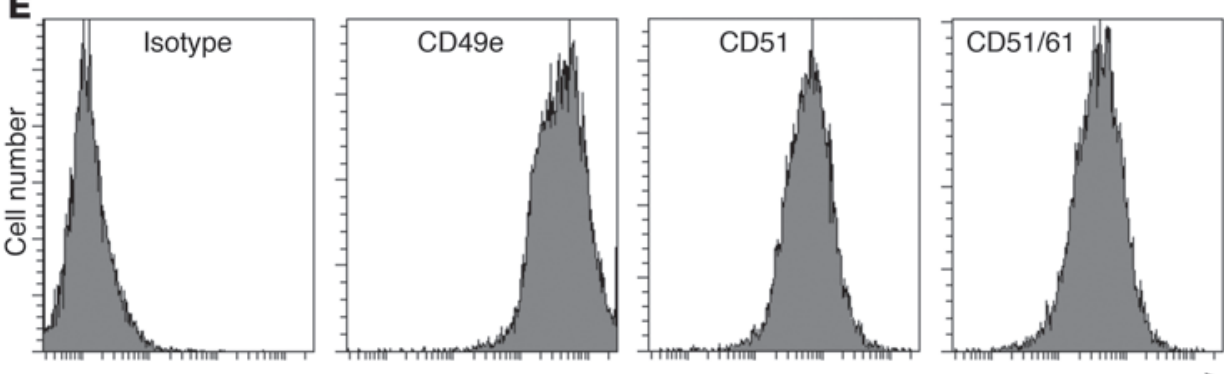

MFI

Figure 1

Expression and functional activity of RDD fusion proteins in vitro. (A) Human fibroblasts transfected with different constructs were analyzed for RDD expression by RT-PCR (lanes: 1, weight marker; 2, untransfected fibroblasts; 3, transfected with $p V A X-$ mock; 4, transfected with $p V A X-R D D$; 5 , transfected with $p V A X-R F P-R D D ; 6$, negative control; 7, plasmid $p V A X-R D D$ [positive control 1]; 8, plasmid $p V A X-R F P-R D D$ [positive control 2]. (B) Murine LL/2 cells were transfected with the $p V A X-R F P-R D D$ or the $p V A X-R F P$ plasmid as indicated. Protein expression was detected by fluorescence microscopy. Original magnification, $\times 400$. (C) HUVEC cultures were scratched in a standardized fashion (wounding of the monolayer), thus creating a cell-free lane (width, $0.5 \mathrm{~mm}$ ) in each culture. Cultures were then incubated with supernatant from untransfected human fibroblasts (circles), from human fibroblasts transfected with the $p V A X$-mock plasmid (squares), or the $p V A X-R D D$ plasmid (triangles). Migration of cells into the cell-free lane was monitored. Each data point represents the mean of 10 measurements ( \pm SD). Units on the $y$-axis: $\mu \mathrm{m}$. ${ }^{* \star \star} P<0.001$. (D) Representative HUVEC cultures described in C. The controls shown here are cultures incubated with supernatant from $p V A X$-mock-transfected fibroblasts, which were similar to the other controls. The margins of the cell layers are indicated by black lines. Original magnification, $\times 100$. (E) Expression of the RDD target proteins, integrins $\alpha_{v} \beta_{3}$ and $\alpha_{5} \beta_{1}$, on HUVEC as detected by flow cytometry. Strong signals are detected with antibodies directed against CD49e ( $\alpha_{5}$ integrin subunit), CD51 ( $\alpha_{v}$ integrin subunit), and a combinatorial epitope of CD51 and CD61 (the $\alpha_{v} \beta_{3}$ integrin heterodimer). 
efficiency, while avoiding the problem of using viral vectors (34, 35 ). In addition, given that electric pulse-mediated transfection of therapeutic genes into skeletal muscle is expected to result in longterm expression $(36,37)$, this strategy appears promising for pilot and proof-of-principle studies.

We have used xenotransplantation of human psoriasis in 2 distinct models (38) as well as a murine psoriasis-like skin disorder in K5.TGF- $\beta 1$ transgenic mice (39) as independent angiogenesisrelated skin disorders (40). In proof-of-principle experiments, we provide the first experimental evidence to our knowledge that non-viral gene therapy by transient expression of the disintegrin domain of ADAM-15 inhibits angiogenesis both in psoriasis and psoriasiform skin inflammation in K5.TGF- $\beta 1$ mice, leading to significant improvement of both diseases.

\section{Results}

A recombinant disintegrin domain inbibits endothelial cell functions in vitro. ADAM-15 is evolutionary highly conserved; the disintegrin domains of murine and human ADAM-15 share amino acid sequence homologies of $77.6 \%$ (41). We have generated a recombinant disintegrin domain (RDD), homologous to murine, human, and bovine ADAM-15 (Supplemental Figure 1; supplemental material available online with this article; doi:10.1172/ JCI41295DS1) that interferes with $\alpha_{5} \beta_{1}$ and $\alpha_{V} \beta_{3}$ integrins of either species (33). In our first series of experiments, the inhibitory capacity of the RDD molecule was demonstrated on cultured endothelial cells. When monolayers were "wounded" by standardized scratching and closure of the cell-free areas was monitored, RDD significantly inhibited the migration of endothelial cells in a dose-dependent fashion. In 4 independent experiments (16-21 individual cultures for each condition), endothelial cell migration in the presence of $15 \mu \mathrm{g} / \mathrm{ml}$ RDD protein was reduced to $54.5 \%( \pm 3.44 \% ; P<0.0001)$ as compared with that of untreated control cultures (Supplemental Figure 2). As detected using Western blot analysis, exposure of cultured endothelial cells to RDD reduced expression of several molecules implicated in signaling or migration, including integrin-linked kinase (ILK), focal adhesion kinase (FAK; also known as protein tyrosine kinase-2 [PTK2]), and activated leukocyte cell adhesion molecule (ALCAM; also known as CD166). Decreased activity of MMP-2 was demonstrated by zymography. In contrast, expression of tissue inhibitor of metalloproteinase- 2 was increased (data not shown).

To demonstrate that RDD secreted by transfected cells impaired endothelial cell functions, normal human fibroblasts (Figure 1A) were transfected by electroporation with different constructs. The RDD-encoding sequence and several control sequences were cloned into the $p V A X 1$ expression vector (Supplemental Figure 1). The respective plasmids, $p V A X$-mock, $p V A X$-red fluorescent protein $(p V A X-R F P), p V A X-R D D$, and $p V A X-R D D-R F P$, were obtained from E. coli bacteria after transformation. Each plasmid construct was sequenced, and no sequence alterations were observed (data not shown). Expression of the RFP-coupled fusion protein of RDD $(p V A X-R D D-R F P)$ as well as the control RFP $(p V A X-R F P)$ could be readily detected within transfected murine cells using fluorescence microscopy (Figure 1B). Morphological changes or altered growth characteristics of the transfectants were not detected (data not shown). HUVEC monolayers, which strongly expressed the RDD target proteins, integrins $\alpha_{v} \beta_{3}$ and $\alpha_{5} \beta_{1}$, were incubated with supernatant from different transfected fibroblast populations, and closure of the cell-free lane (artificial wound generated by stan- dardized scratching) was monitored microscopically for up to 29 hours. Cultures incubated with supernatant from RDD-expressing transfectants but not controls showed markedly delayed migration of endothelial cells into the gap $(P<0.0001$ at all measured time points, i.e., 6,12 , and 24 hours), indicating functional activity of RDD secreted by transfectants (Figure 1, C and D). RDD target proteins were highly expressed in HUVECs (Figure 1E).

Expression of RDD in vivo. The next series of experiments was designed to achieve in vivo expression of the antiangiogenic peptide by non-viral gene therapy. Toward this end, the plasmids were transfected into the calf muscles (musculus [m.] tibialis cranialis) of mice by DNA electrotransfer, using an adjusted protocol with an initial high-voltage pulse $(700 \mathrm{~V} / \mathrm{cm}, 100 \mu \mathrm{s})$ and 8 subsequent low-voltage pulses $(100 \mathrm{~V} / \mathrm{cm}, 50 \mathrm{~ms})$, a procedure that had been optimized in an extensive series of preliminary experiments (data not shown) (42). This combination of pulses facilitates gentle cell permeabilization, followed by electrophoresis of the plasmids into the cells, while largely avoiding damage to the overlying skin and other adjacent tissues $(34,43)$. In order to determine the persistence of the transgene in various tissues of the body, both male and female mice were analyzed for up to 4 months after somatic gene therapy with RDD. Vehicle-treated mice were analyzed as controls. It was found that the transgene was below the level of quantification, as determined by quantitative PCR in all tissues, including the gonads. Only in the treated muscles was the transgene detectable by the end of the observation period, albeit expression levels were diminished by approximately 3 logs compared with those at the early time points (data not shown).

Fluorescence microscopy demonstrated clear red signals within the calf muscles of mice transfected with the $p V A X-R D D-R F P$ fusion protein or $p V A X-R F P$ (Figure $2 \mathrm{~A}$ ). In addition, immunohistochemistry was performed to confirm the topographic mapping of the transgene within the skeletal muscle fibers (Figure 2B). Time course experiments revealed that expression of the transgenes was detectable as early as 24 hours after electrotransfer, reached a peak after 3 days and tapered off within 2-3 weeks (data not shown). Inflammatory reactions at the transfection sites or other unwanted side effects were not observed (data not shown). Of note, when organs distant from the transfection site were analyzed in mice transfected with the $p V A X-R D D-R F P$ construct, clear fluorescence signals were detected within the cutaneous connective tissue but not the epidermis (Figure 2A). In contrast, control animals transfected with RFP alone or mock-transfected animals did not show dermal fluorescence (Figure 2A), suggesting that RDD-containing peptides became deposited within the skin. The results obtained by fluorescence microscopy were confirmed using immunohistochemistry, again showing deposition of the RDDcontaining products but not the controls in the vicinity of some blood vessels (Figure 2C). Deposition of the RDD-RFP peptide in other organs, including muscle, liver, and kidneys (only single cells showed weak reactivity; data not shown), was weak, if detectable at all, and morphological alterations in other organs were not detected (data not shown). As demonstrated by Western blot analysis using RFP-specific antibodies, secreted protein could be detected within the serum of mice ( $n=4$ mice) transfected with the $p V A X-R D D-R F P$ construct (Figure 2D). Since no signal was detected when mice were treated with $p V A X-R F P(n=4$ mice), these results suggested that $\mathrm{RDD}$-containing sequences were readily secreted (Figure 2D).

To exclude toxicity, a repeated toxicity study (4 intramuscular administrations in 1-week intervals) was performed in both male 
A
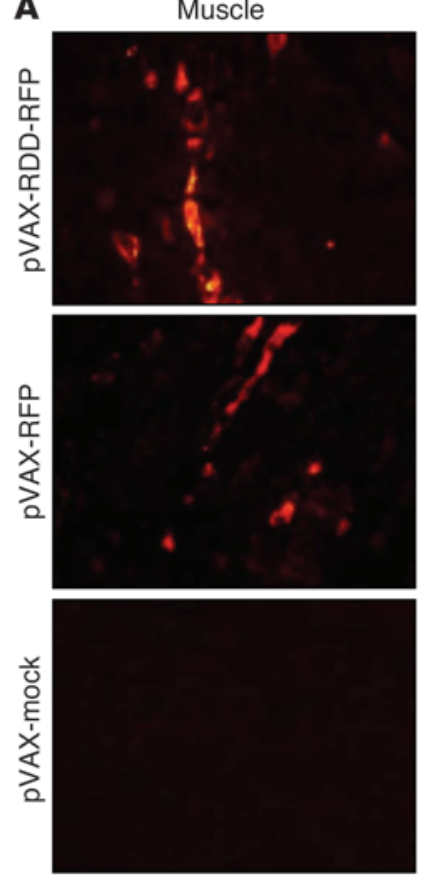

Skin
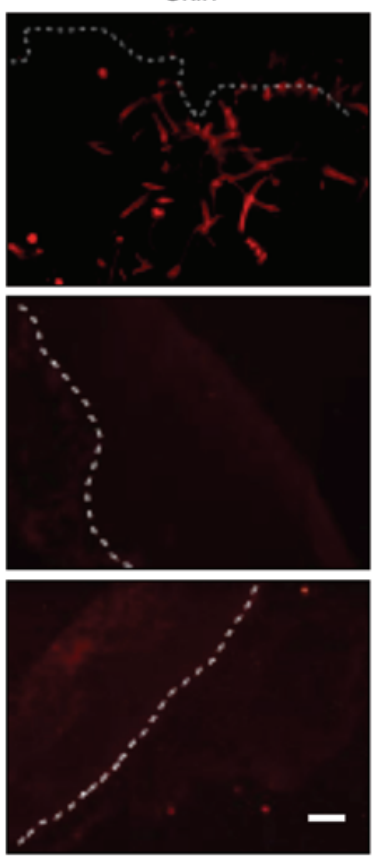

B

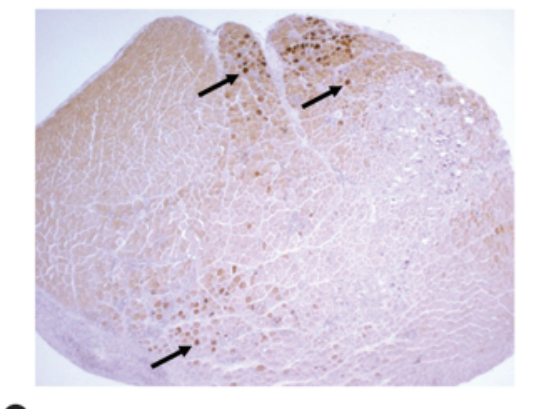

C

pVAX-RDD-RFP

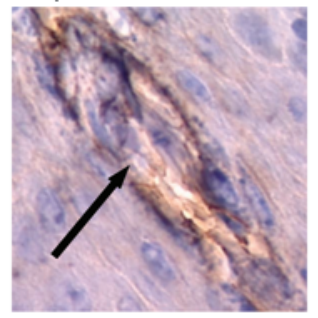

D

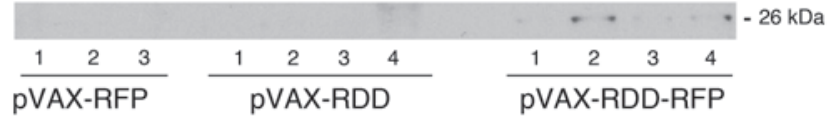

Figure 2

Expression and dermal deposition of RDD fusion proteins in vivo. (A) Prkdcscid mice were transfected with $p V A X-R D D-R F P, p V A X-R F P$, or $p V A X-m o c k$ by in vivo electroporation of the tibialis cranialis muscle as indicated. After 3 days, fluorescence was detected in the transfected tibialis cranialis muscle (left panels) and the skin (right panels). Dashed lines indicate the dermo-epidermal junction. Both RFP-containing products are expressed in the muscle tissue, but only RDD-containing products are deposited in the skin. Scale bar: $20 \mu \mathrm{m}$. (B) The skeletal muscle of a Prkdc scid mouse transfected with pVAX-RDD-RFP (14 days after electrotransfer of the gene construct) was subjected to immunohistochemistry to allow topographic mapping of the transgene within the skeletal muscle. Arrows point to examples of positive cross-cut fibers. Original magnification, $\times 25$. (C) High-power magnification of skin sections of a Prkdc scid mouse transfected with $p V A X-R D D-R F P$ (left panel) and a Prkdc scid mouse transfected with $p V A X-R F P$ (right) that were stained immunohistochemically using a RFP-directed antibody. Only blood vessels (arrows) in the mouse transfected with the RDD-containing construct, but not those of the RFP control, light up, thus indicating deposition of RDD-containing gene products in the vicinity of cutaneous blood vessels. Scale bar: $20 \mu \mathrm{m}$. (D) Mice were treated by somatic gene therapy using the $p V A X-R F P$ ( $n=3$ mice), $p V A X-R D D$ ( $n=4$ mice), or the $p V A X-R D D-R F P$ ( $n=4$ mice) construct as indicated. Secreted protein was detected by Western blot analysis using an RFP-directed antibody. Only mice transfected with the $p V A X-R D D-R F P$ construct exhibit a signal, suggesting that secretion into the circulation is dependent on the presence of the RDD sequence.

and female mice. Animals were sacrificed just after the last administration or 1 month after the last administration. No pathological alterations were detected clinically and histopathologically in various tissues, including the gonads (data not shown). With the exception of a reversible inflammatory reaction within the injected muscle, wild-type immunocompetent mice did not show any signs of adverse effects.

In vivo RDD gene therapy stops psoriasiform changes in K5.TGF- $\beta 1$ transgenic mice. Having established that non-viral gene transfer could be successfully applied in vivo, the impact of RDD expression on cutaneous vascularization and the course of the psoriasis-like disorder in K5.TGF- $\beta 1$ transgenic mice (39) was assessed. In a series of preparatory experiments, it was established that K5.TGF- $\beta 1$ transgenic mice showed significantly increased size and density of cutaneous blood vessels (Figure 3A). As an independent second method, blood flow within the upper plexus of the skin was assessed at several time points for up to 12 days by high-resolution ultrasound. In order to achieve a reliable and reproducible functional quantification of the cutaneous blood flow (which shows considerable site-dependent variability), 4 areas distant from the transfection sites ( 2 on the abdomen and 1 on each thigh) were analyzed in a standardized manner (Supplemental Figure 3), and the mean blood flow from all 4 areas was calculated for each mouse. Again, this standardized functional approach demonstrated significantly increased vascularization and blood flow in K5.TGF- $\beta 1$ transgenic mice compared with that in wild-type mice (14.3\% of the total dermal volume $[ \pm 4.1 \%]$ in wild-type and $26.9 \%$ $[ \pm 5.4 \%]$ in K5.TGF- $\beta 1$ transgenic mice; $P<0.001$; Figure $3 \mathrm{~B})$.

To determine the optimal concentration of RDD plasmid for transfections, we injected anesthetized K5.TGF- $\beta 1$ transgenic mice intramuscularly with 3 different doses of the $p V A X-R D D$ plasmid $(12.5,25$, or $50 \mu \mathrm{g}$ per hind leg, the latter dose being the highest that was tolerable without injection-related side effects) and performed electrotransfer. Given that $50 \mu \mathrm{g} p V A X-R D D$ plasmid yielded the strongest diminution of the cutaneous blood flow (Figure 3C), all experiments were performed using $50 \mu \mathrm{g}$ plasmid in each calf muscle.

When K5.TGF- $\beta 1$ transgenic mice ( $n=8$ mice per group) were subjected to electroporation only (PBS control), $p V A X$ electroporation (mock transfection control), or $p V A X-R D D$ electroporation 
A

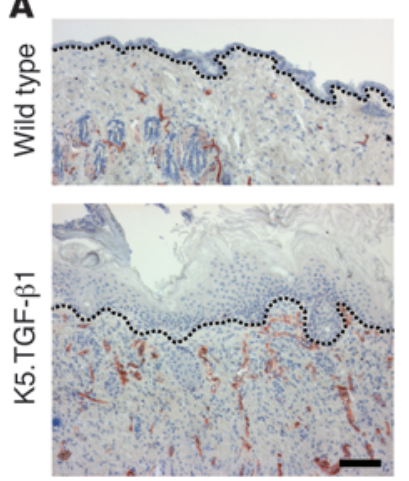

C
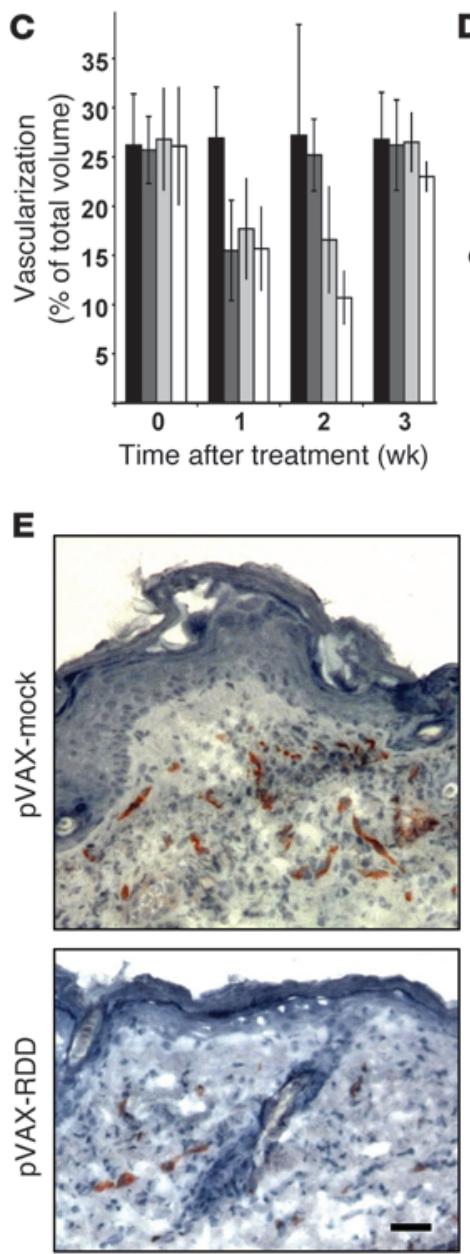

B
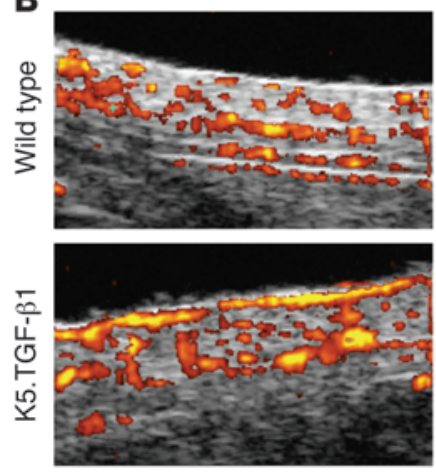

D 1.4

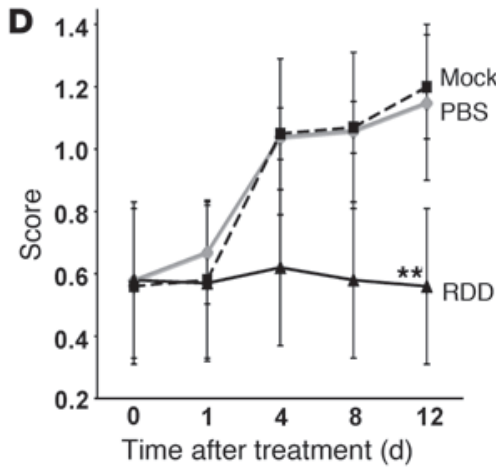

$\mathbf{F}$

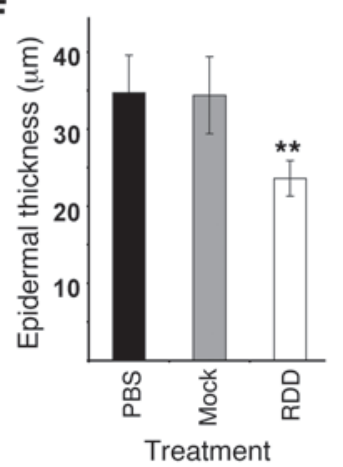

\section{Figure 3}

Therapeutic efficacy of RDD gene therapy in K5.TGF- $\beta 1$ transgenic mice. (A) Immunohistochemical analysis of CD31 in back skin of a wild-type and a K5.TGF- $\beta 1$ transgenic littermate. Transgenic skin shows more and larger blood vessels than wild-type skin. Scale bar: 50 um. Dashed lines, dermo-epidermal junction. (B) Blood flow within the upper cutaneous plexus was analyzed in vivo in a wild-type (top) and a K5.TGF- $\beta 1$ transgenic mouse (bottom) by high-resolution Doppler ultrasound. Flowing blood as a surrogate marker for vascularization is visualized as yellow and red. Original magnification, $\sim \times 100$. (C) K5.TGF- $\beta 1$ transgenic mice ( $n=4$ in each group) were subjected to gene therapy with $p V A X$-mock (black bars) or $p V A X-R D D$ at doses of $12.5 \mu \mathrm{g}$ (dark gray bars), $25 \mu \mathrm{g}$ (light gray bars), or $50 \mu \mathrm{g}$ (white bars). The cutaneous blood flow in all mice was determined by high-resolution Doppler ultrasound. (D) Clinical severity scores in K5.TGF- $\beta 1$ transgenic mice ( $n=8$ in each group) subjected to electroporation only (PBS, gray diamonds) or to gene therapy with $p V A X-m o c k$ (filled squares) or $p V A X-R D D$ (triangles) were monitored. Values represent mean $\pm \mathrm{SD}$. ${ }^{*} P<0.01$. (E) Cryostat-cut skin sections of a K5.TGF- $\beta 1$ transgenic mouse subjected to gene therapy using the $p V A X$-mock plasmid (top panel) and a littermate treated with $p V A X-R D D$ (bottom panel) were analyzed by immunohistochemistry using a CD31-directed antibody 12 days after treatment. Scale bar: $20 \mu \mathrm{m}$. (F) Morphometric analysis of epidermal thickness in K5.TGF- $\beta 1$ transgenic mice ( $n=8$ in each group) subjected to electroporation only (PBS, black bar) or to gene therapy with $p V A X$-mock (gray bar) or $p V A X-R D D$ (white bar). ${ }^{* *} P<0.01$ compared with the pVAX-mock controls. and monitored for 12 days, some remarkable effects of RDD on the psoriasiform phenotype became apparent. While the disease severity score showed the expected worsening in both control groups (scores $1.15[ \pm 0.25]$ and $1.20[ \pm 0.17]$, respectively, by the end of the observation period), disease progression was completely stopped in the group treated by RDD gene therapy (score 0.56 $[ \pm 0.25] ; P<0.01$ compared with the $P V A X$-mock control group; Figure $3 \mathrm{D})$. End-point analysis by immunohistochemistry and subsequent morphometric analysis confirmed the in vivo observations: RDD gene therapy resulted in significantly reduced cutaneous vascularization (overall reduction of CD31-positive blood vessels of $25 \%$ compared with that of either of the controls, as determined by morphometric analyses; $P<0.01)$. Thus, morphometric analyses (performed as a second independent method) confirmed the results obtained by Doppler ultrasound. Likewise, gene therapy with RDD led to significantly reduced epidermal thickness (reduction of $32 \%$; $P<0.01$; Figure $3, \mathrm{E}$ and $\mathrm{F}$ ). The number of cutaneous T lymphocytes was not significantly affected by RDD gene therapy (epidermal $\mathrm{CD}^{+} \mathrm{T}$ cells, $14[ \pm 7]$ per $\mathrm{mm}$ in control mice and 10 $[ \pm 8]$ per $\mathrm{mm}$ in mice treated with $p V A X-R D D$; CD $4^{+}$epidermal cells, $21[ \pm 12]$ per $\mathrm{mm}$ in control mice and $16[ \pm 10]$ per $\mathrm{mm}$ in mice treated with $p V A X-R D D)$. 
A

No PBMC

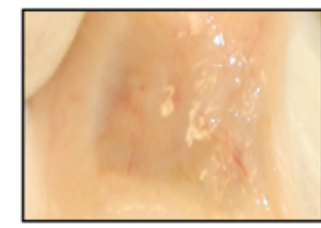

B
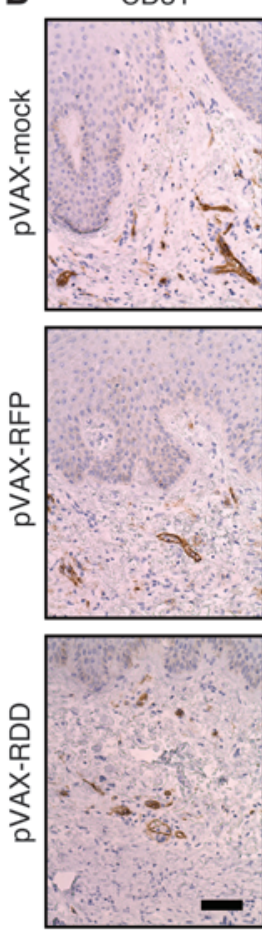

C
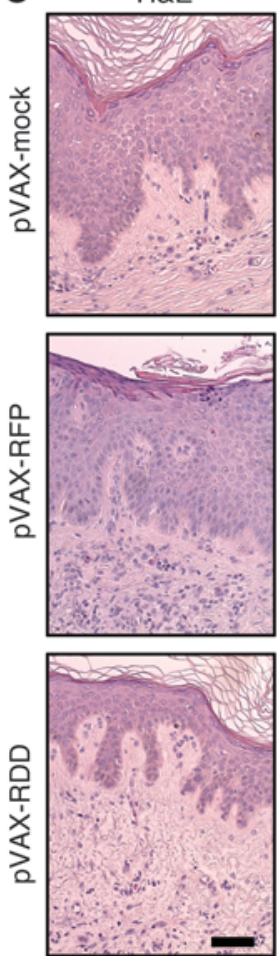

PBMC pVAX-mock

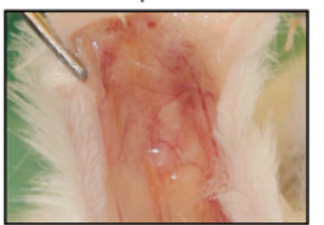

CD31
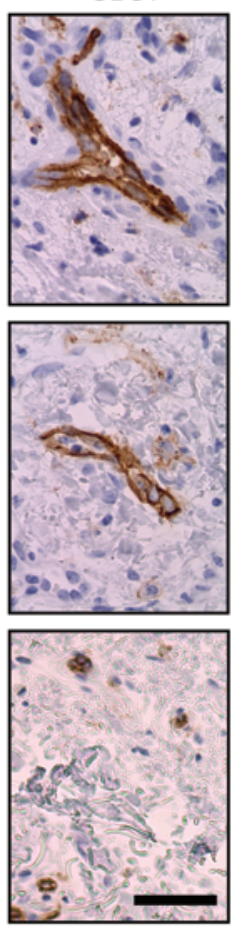

Ki67
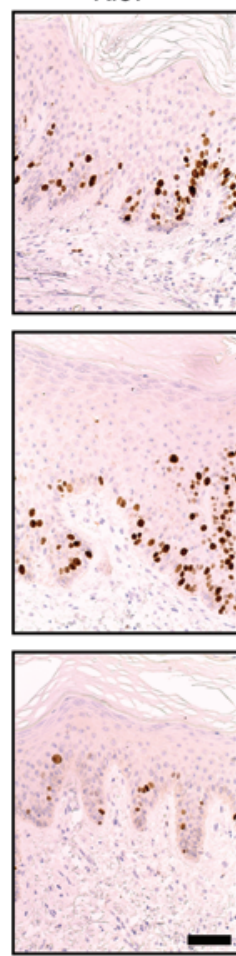

CD3
PBMC pVAX-RDD

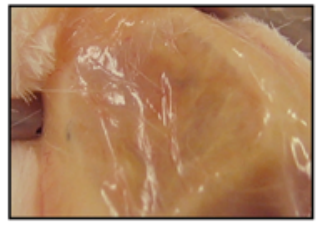

BS-1
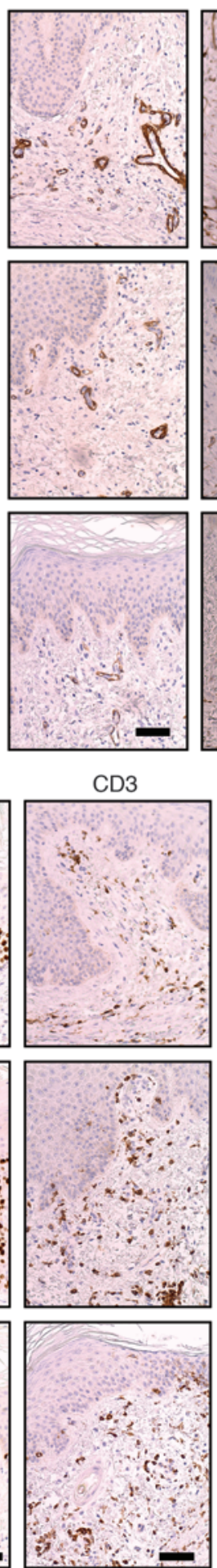
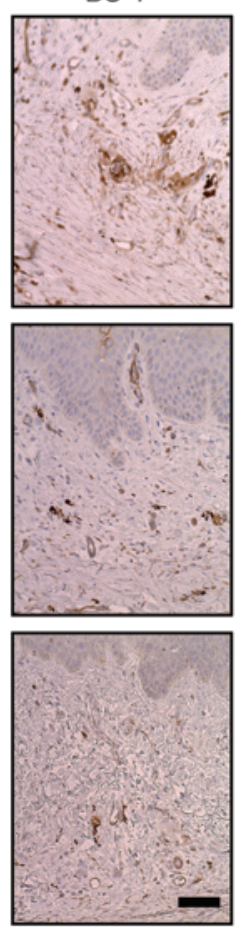

D
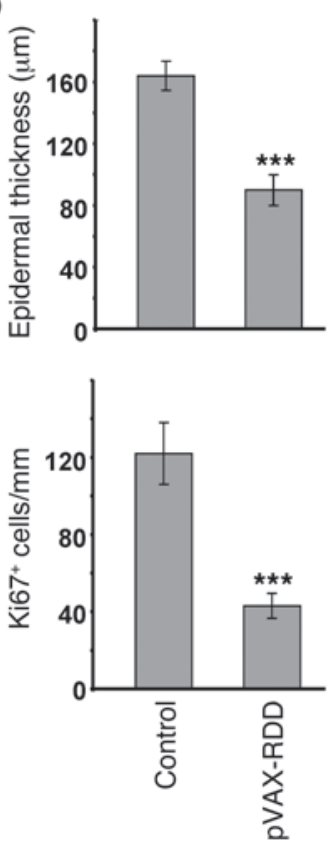

Figure 4

RDD gene therapy prevents the development of psoriasis in the hu/SCID xenotransplantation model. (A) Uninvolved skin from psoriasis patients was transplanted onto immunodeficient Prkdc scid mice, and recipient mice were injected intraperitoneally with PBS (left panel) or $10^{7}$ activated PBMCs from the same donors to induce psoriasis (middle and right panels). Two days prior to injection of PBMCs, the mice were subjected to gene therapy with $p V A X$-mock or $p V A X-R D D$. The macroscopic aspect of the blood vessels on the underside of the skin transplants demonstrates that gene therapy with RDD markedly reduced cutaneous vascularization. Original magnification, $\sim \times 3$ (B) Prkdcscid mice were treated as described in $\mathbf{A}$, and the transplanted human skin was analyzed by immunohistochemistry using the indicated reagents detecting blood vessels. Somatic gene therapy with $p V A X-R D D$, but not that with $p V A X$-mock or $p V A X-R F P$, reduces number and size of cutaneous blood vessels of both human (CD31 and $\alpha \mathrm{SMA}$ ) and murine (BS-1) origin. Scale bar: $50 \mu \mathrm{m}$. (C) Human skin transplants from Prkdc scid mice were further analyzed by H\&E staining (left panels) and by immunohistochemistry using the indicated antibodies detecting proliferating cells (Ki67) or T cells (CD3). Both the epidermal thickness and the number of proliferating epidermal keratinocytes are reduced in transplants from mice treated by RDD gene therapy. Scale bar: $50 \mu \mathrm{m}$. (D) Quantitative morphometric analysis of transplants from Prkdcscid mice. The top graph depicts epidermal thickness as determined by blinded measurements. The bottom graph shows the number of proliferating epidermal cells in mice subjected to RDD gene therapy compared with that of the controls. ${ }^{* * *} P<0.001$. Values represent mean \pm SD. 
Antiangiogenic RDD gene therapy prevents psoriasis in an inducible xenotransplantation model. Having shown that RDD gene therapy was efficacious in K5.TGF- $\beta 1$ transgenic mice, we next assessed whether this antiangiogenic gene therapy would affect the pathogenesis of human psoriasis in the psoriasis/SCID mouse xenograft model, in which human skin was transplanted onto Prkdcsid mice (38) and which allows the study of psoriasis development in connection with angiogenesis (44). After several preliminary experiments in which it was established that in vivo RDD expression can be used in the xenotransplantation models, noninvolved skin from psoriasis patients (4 patients, each biopsied piece of skin yielding $>6$ transplants) was transplanted, and psoriasis was induced by injection of staphylococcal enterotoxin B (SEB) and IL-2-stimulated autologous PBMCs $(38,44)$. The DNA electrotransfer using $50 \mu \mathrm{g} p V A X-R D D$ or $p V A X-R F P$ (into both tibialis cranialis muscles) was performed 2 days prior to the induction of psoriasis. Disease development was monitored for 14 days.

Psoriasis induction in the transplants was accompanied by profoundly increased vascularization, both macroscopically (Figure 4A) and histopathologically (Figure 4B). Given that the grafts may harbor blood vessels of both human and murine origin (45), we evaluated the effect of RDD using several staining methods. Human-derived vessels were detected using antibodies directed against human CD31 (also known as PECAM-1) and $\alpha$-SMA. Murine endothelial cells were stained using anti-mouse BS-1lectin. Of note, gene therapy with RDD resulted in marked reduction of cutaneous blood vessels compared with those of controltreated mice (Figure 4, A and B). Morphometric analysis revealed reduction of $42 \%(P<0.001$, comparing vascularization of control [pVAX] and RDD-treated mice).

When other features of psoriasis were assessed morphometrically, highly significant effects were observed regarding epidermal thickness and numbers of proliferating cells detected by reactivity with the Ki67 mAb. The epidermal thickness (measured in 8 to 10 randomly chosen sites in the middle of each graft in a blinded fashion) was $162.5 \mu \mathrm{m}(\mathrm{SD}=9.7)$ in the control $p V A X-R F P$-treated mice $(n=9)$ and $89.7 \mu \mathrm{m}(\mathrm{SD}=9.8)$ in the $p V A X-R D D$-treated mice $(n=15$; reduction of $45 \% ; P<0.001$; Figure 4 , C and D). In addition, the numbers of proliferating epidermal cells showed highly significant differences between controls and RDD-treated mice $(121.5$ cells $/ \mathrm{mm}[\mathrm{SD}=15.9]$ in $p V A X-R F P$-treated mice and 42.9 cells $/ \mathrm{mm}[\mathrm{SD}=6.0]$ in $P V A X-R D D$-treated control mice; reduction of $65 \%$; $P<0.01$; Figure $4, C$ and $D)$, indicating that the primary effect of RDD gene therapy on cutaneous vascularization indeed alleviated typical epidermal features of psoriasis. Numbers of cutaneous $\mathrm{T}$ cells were not significantly different in RDD-treated versus control-treated mice $\left(12[ \pm 4] \mathrm{CD}^{+}\right.$epidermal cells $/ \mathrm{mm}$ in control mice vs. $9[ \pm 5] \mathrm{CD}^{+}$epidermal cells $/ \mathrm{mm}$ in $p V A X-R D D-$ treated animals; Figure 4C). There were slightly reduced numbers of Mac-1-expressing cells (predominantly macrophages and dendritic cells; $35[ \pm 21]$ cells $/ \mathrm{mm}$ in control mice vs. $24[ \pm 14]$ cells/mm in mice treated with $p V A X-R D D$ gene therapy). Likewise, when skin sections were stained for CD1a, detecting epidermal Langerhans cells in human skin transplants, $39( \pm 22)$ cells $/ \mathrm{mm}$ epidermis were seen in control animals, whereas the respective number was $23( \pm 16)$ cells $/ \mathrm{mm}$ in transplants from mice treated with $p V A X-R D D$ gene therapy (see below). A similar tendency was seen when expression of CD68, a marker for dermal macrophages, was assessed (data not shown). However, those differences did not reach statistical significance.
Therapeutic efficacy of RDD gene therapy on fully developed psoriatic phenotype. We next assessed the impact of halting angiogenesis by RDD gene therapy on full-fledged human psoriatic skin (4 patients, each biopsy specimen yielding $>8$ transplants). The treatment was administered 14 days after transplantation as intramuscular injection of $50 \mu \mathrm{g} p V A X-R D D$ or the control $p V A X-R F P$ in both $\mathrm{m}$. tibialis cranialis and subsequent electroporation. The conspicuously prominent vascularization visible on the undersides of the transplanted skin flaps in the control mice was markedly reduced in mice treated by RDD gene therapy (Figure 5A). This macroscopic feature was paralleled by markedly reduced vascularization on the microscopic level (Figure 5B), indicating that in vivo expression of the RDD fragment caused diminution of number and size of the hypertrophic cutaneous microvessels. Morphometric analysis revealed reduction of $46 \%(P<0.001$ comparing vascularization of control [pVAX] and RDD-treated mice).

Of note, RDD transfection also led to significantly reduced epidermal thickness and numbers of proliferating cells compared with those of the controls. The epidermal thickness was 166.85 $\mu \mathrm{m}(\mathrm{SD}=12.1)$ in $p V A X-R F P$-treated mice $(n=14$ animals $)$ and $88.29 \mu \mathrm{m}(\mathrm{SD}=7.7)$ in $p V A X-R D D$-treated mice $(n=13$ animals; $P<0.001$; Figure 5, C and D). Likewise, the numbers of proliferating epidermal cells were significantly reduced in RDD-treated mice $(312.0$ cells $/ \mathrm{mm}[\mathrm{SD}=48.3]$ in $p V A X-R F P$-treated mice and 42.5 cells $/ \mathrm{mm}[\mathrm{SD}=14.2]$ in $p V A X-R D D$-treated mice; $P<0.001$; Figure 5, C and D). Finally, somatic gene therapy using RDD led to reduced expression of HIF1 $\alpha$ and FLT1 (expressed by endothelial cells) in the dermal compartment of the skin, whereas expression of angiopoietin-1 and VEGFA remained unchanged compared with that of control animals (Figure 6).

Thus, antiangiogenic gene therapy was highly efficacious both in the prevention and treatment of psoriasis lesions in vivo.

\section{Discussion}

Following early reports suggesting that angiogenesis plays a role in psoriasis (13, 46-49), specific modulation of dysregulated vascularization is currently evolving into a hot research topic $(17,26$, 50-54). However, direct evidence to corroborate this hypothesis is still scant. A VEGF-directed antibody led to complete remission of psoriasis in 1 patient (55). In addition, several transgenic mouse models have been generated to clarify whether angiogenesis-related factors can initiate psoriasiform pathologies (40). For example, targeting VEGF overexpression to the epidermis $(56,57)$ or transgenic overexpression of Tie-2 resulted in psoriasis-like features (58). In addition, several mouse models generated by manipulations unrelated to angiogenesis, such as adoptive transfer of minor histocompatibility-mismatched $\mathrm{CD}^{+} / \mathrm{CD} 45 \mathrm{RB}^{\text {hi }} \mathrm{T}$ cells into immunodeficient recipients (59) or K5.TGF- $\beta 1$ transgenic mice (39), feature increased size and density of cutaneous blood vessels. Based on this briefly delineated circumstantial evidence, it is reasonable to assume that direct targeting of cutaneous angiogenesis will be efficacious to treat psoriasis. In this context, we provide experimental in vivo proof of concept that halting angiogenesis can indeed alleviate psoriasis.

Using K5.TGF- $\beta 1$ transgenic mice and 2 independent human/ mouse transplantation models, we demonstrate the principle that psoriasis and related skin disorders can be alleviated by an innovative non-viral RDD-based antiangiogenic gene therapy that results in transient inhibition of angiogenesis. It is conceivable that this approach will be used in the future to express other therapeutic 
A
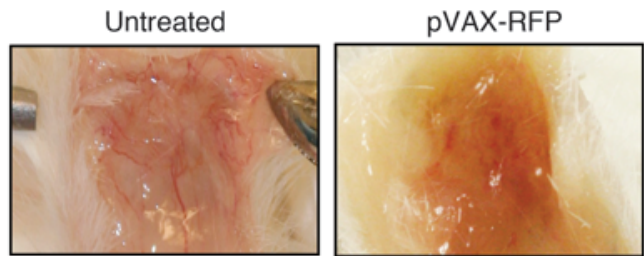

B
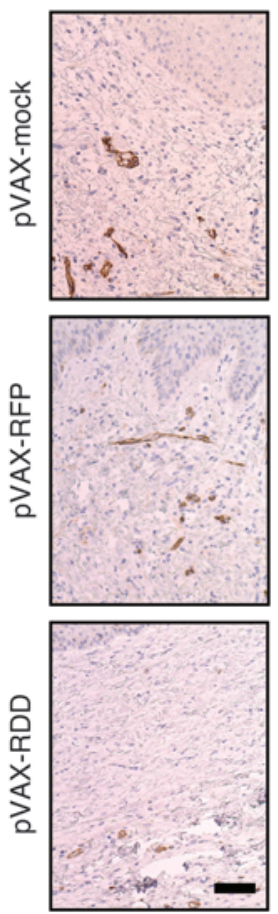

C
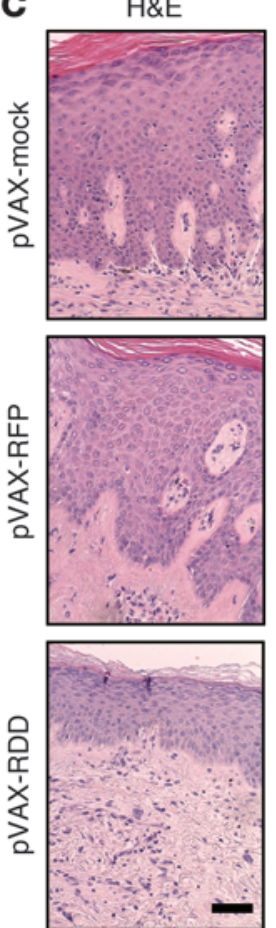

CD31
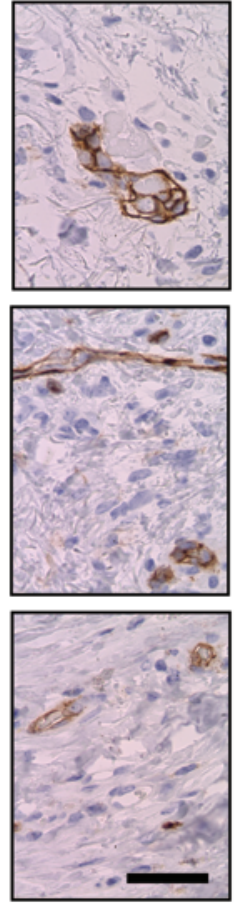

Ki67
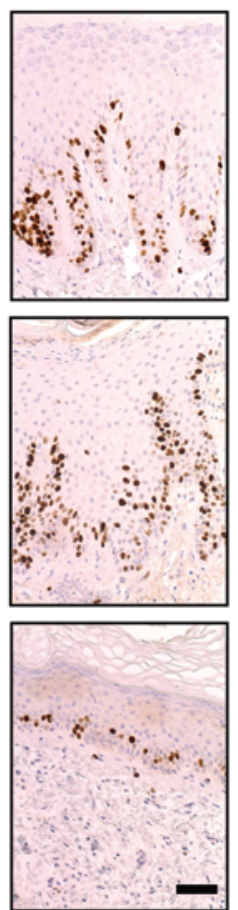

aSMA
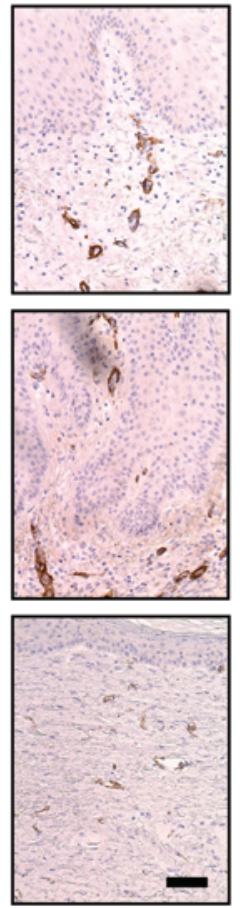

CD3
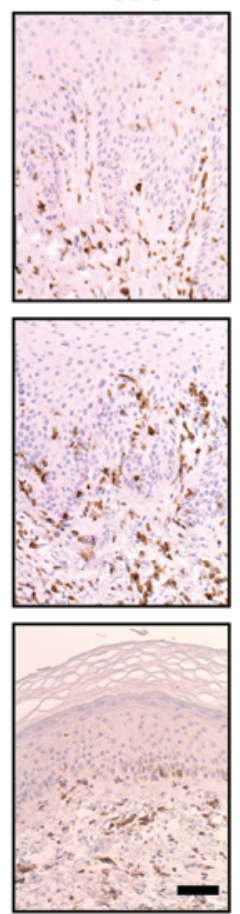

pVAX-RDD

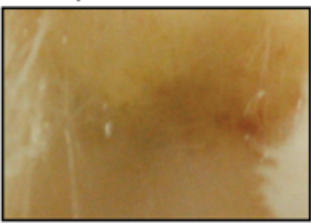

BS-1
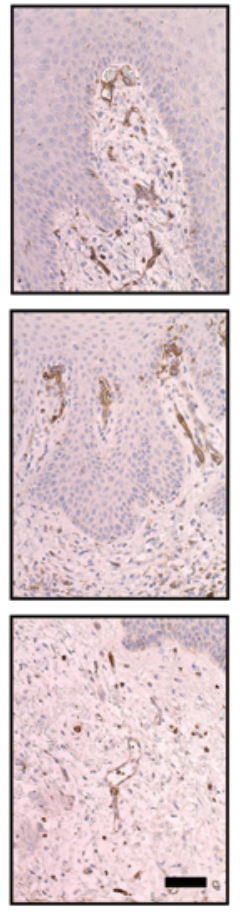

D

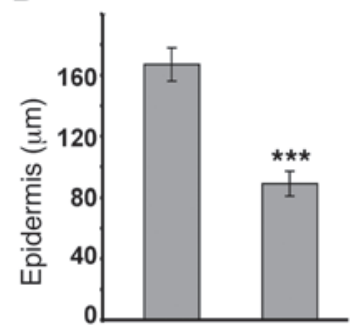

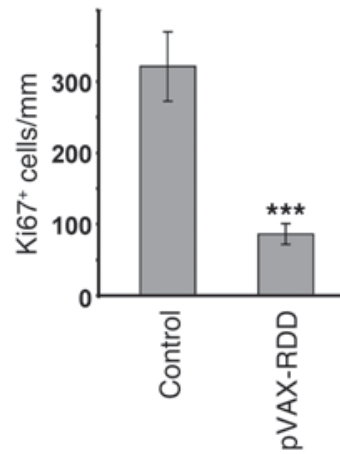

\section{Figure 5}

RDD gene therapy reduces cutaneous vascularization and alleviates psoriasis in human skin transplanted onto immunodeficient mice. (A) Psoriatic skin with a full-fledged phenotype was transplanted onto Prkdcscid mice, and recipient mice were either left untreated (representative of $n=12$ mice) or subjected to gene therapy with $p V A X-R F P$ (representative of $n=14$ mice) or $p V A X-R D D$ (representative of $n=13$ mice). The macroscopic aspect of the blood vessels on the underside of the skin transplants demonstrates that gene therapy with RDD reduces cutaneous vascularization. Original magnification, $\sim \times 3$. (B) Transplanted psoriatic skin was analyzed by immunohistochemistry using the indicated reagents detecting blood vessels. Somatic gene therapy with $p V A X-R D D$ results in reduction of both number and size of cutaneous blood vessels as compared with that of the controls. Blood vessels of human (CD31 and SMA) as well as murine (BS-1) origin are affected. Scale bar: 50 $\mu \mathrm{m}$. (C) Transplants of fully developed psoriasis transplanted onto Prkdc scid mice were further analyzed by staining with H\&E (left panels) or by immunohistochemistry using the indicated antibodies detecting proliferating cells (Ki67) or T cells (CD3). Both the epidermal thickness and the number of proliferating epidermal keratinocytes are reduced in transplants from mice treated by RDD gene therapy. Scale bar: $50 \mu \mathrm{m}$. (D) Quantitative morphometric analysis of transplants from Prkdc scid mice. The top graph depicts the epidermal thickness as determined by blinded measurements. The bottom graph shows the number of proliferating epidermal cells in mice subjected to RDD gene therapy compared with that of the controls. Values represent mean $\pm S D$. ${ }^{\star \star *} P<0.001$. 
A

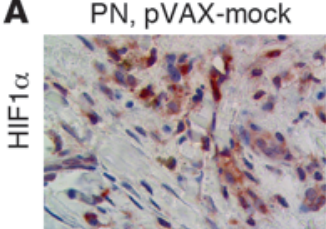

PP, pVAX-mock

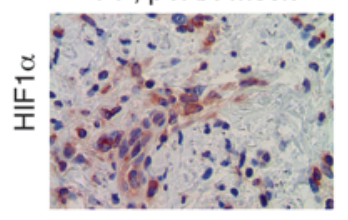

B PN, pVAX-mock

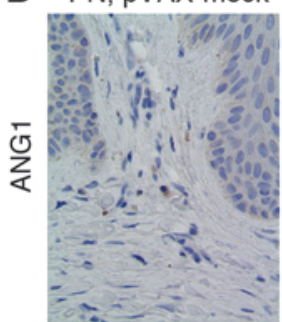

C $\mathrm{PN}, \mathrm{pVAX}$-mock
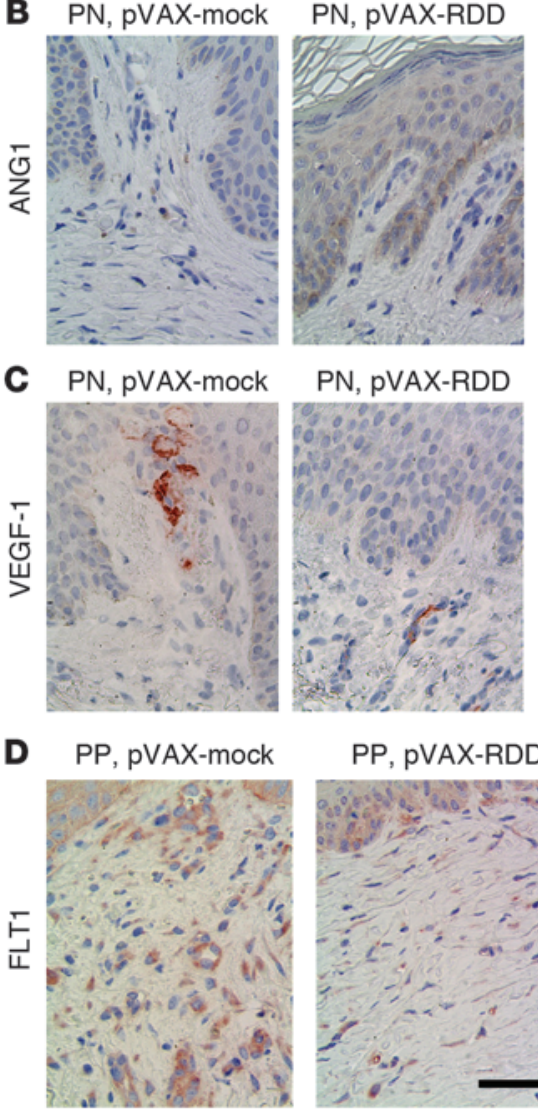

PP, pVAX-RDD

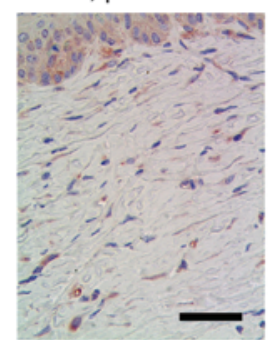

E
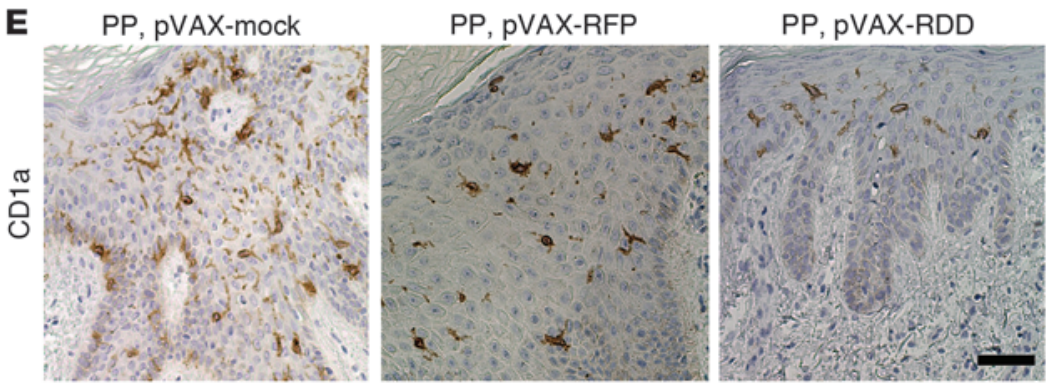

D PP, pVAX-mock

\section{Figure 6}

RDD gene therapy and mediators of endothelial functions in psoriatic skin transplanted onto immunodeficient mice. (A) Uninvolved skin from psoriasis patients was transplanted onto immunodeficient Prkdcscid mice, and the recipient mice were treated as outlined in Methods to induce psoriasis (PN, top row), or psoriatic skin with a full-fledged phenotype (PP, bottom row) was transplanted onto Prkdc scid mice. The recipient mice were either subjected to control treatment using $\mathrm{pVAX}$-mock or $p V A X-R F P$ or $p V A X$ $R D D$. Expression of $\mathrm{HIF} 1 \alpha$ was detected by immunohistochemistry. Scale bar: $50 \mu \mathrm{m}$. (B) Expression of angiopoietin-1 (ANG1) was detected by immunohistochemistry in transplants from mice treated as described in A. Scale bar: $50 \mu \mathrm{m}$. (C) Expression of VEGF-1 was detected by immunohistochemistry in transplants from mice treated as described in $\mathbf{A}$. Scale bar: $50 \mu \mathrm{m}$. (D) Expression of FLT1 was detected by immunohistochemistry in transplants from mice treated as described in A. Scale bar: $50 \mu \mathrm{m}$. (E) Expression of $\mathrm{CD} 1$ a was detected by immunohistochemistry in psoriatic transplants from mice treated as described in $\mathbf{A}$. Scale bar: $50 \mu \mathrm{m}$.

expression has non-angiogenesis-related effects (because the target proteins may be expressed by several cell types), no such effects have been observed in our experiments. An exception may be the observed tendency (which was not statistically significant) toward reduced macrophages and dendritic cells in RDD-treated mice, an effect that might have contributed to the overall therapeutic efficacy of RDD gene therapy. When the RDD-RFP fusion protein was expressed in vivo, deposition was only observed within the dermal connective tissue, i.e., the compartment in which angiogenesis occurs. In addition, it is known that ADAM-15 regulates angiogenesis through its disintegrin-like domain that binds to the $\alpha_{v} \beta_{3}$ integrin (41). Given that $\alpha_{v} \beta_{3}$ is upregulated in lesional dermal vessels in psoriasis as well as in the active psoriasis xenograft model, this receptor presumably contributes to dermal angiogenesis (44, 61). It is thought that RDD interferes with signal transduction by its target receptors, a notion that is supported by decreased expression or activity of ILK, FAK, MMP-2, and ALCAM on cultured endothelial cells upon exposure to RDD. On the cellular level, binding of the RGD motif of ADAM- 15 to the $\alpha_{v} \beta_{3}$ and $\alpha_{5} \beta_{1}$ integrins led to enhanced cell-cell interactions in a recent study, indicating that ADAM-15 plays a role in cell signaling events $(32,62-64)$. As suggested by our experiments, RDD-based gene therapy interfered transiently with important endothelial cell functions in vivo, thus resulting in reduced cutaneous vascularization in conditions with hypervascularization.

molecules interfering with angiogenesis, such as components of the VEGF signaling pathway. Alternative or improved methods of gene delivery, such as microneedles in the skin, might also be promising future directions $(34,60)$. While it is possible in principle that $\mathrm{RDD}$
Non-viral gene delivery methods have attracted considerable interest in recent years (34). However, a drawback is the low efficiency of naked DNA gene transfer compared with that of viral delivery methods. In vivo electroporation to facilitate gene transfer 
shows high rates of transfection in several tissue types and avoids the problems associated with viral vectors $(34,35)$. Indeed, electrotransfer of a plasmid coding for IL-12 to metastatic melanomas resulted in increased IL-12 levels, tumor necrosis, and a lymphocytic infiltrate. In 8 out of 19 patients, disease stabilization or partial remission occurred, and in 2 patients, even non-treated distant lesions showed complete regression (65). In a preclinical study using collagen-induced arthritis in mice, intraarticular DNA electrotransfer of plasmids encoding for soluble TNF receptor variants led to decreased ankle joint destruction (66), underscoring the potential of DNA electrotransfer in inflammatory diseases.

Vector-directed immune responses are a major challenge with all types of gene therapy. Plasmid DNA vectors rapidly stimulate the innate immunity via TLR activation on leukocytes, and specific cellular and humoral responses may occur within a few days (67). Thus far, we have not observed abnormal immune responses in our models. However, since we have used mice with altered immune-related phenotypes, potential immune reactions need to be investigated in further studies.

Plasmid DNA electrotransfer is an attractive approach for systemic transgene delivery to patients with psoriasis. However, in this proof-of-concept study, we used a constitutive promoter. For future clinical applications, it may be advantageous to regulate gene expression or to implement tissue/cell-specific expression. Exogenous compounds, such as the doxycycline-dependent Tet-on system (68), the GeneSwitch system, which uses progesterone antagonists (69), or tissue-specific promoters (70), can control transgene expression through inducible ligand-dependent promoter complexes. Recently, it was shown that it is possible to restrict the expression of a DNA plasmid to keratinocytes using a keratin 14 promoter and to mature dendritic cells using a facin promoter (71). DNA electrotransfer to the readily accessible skin is an attractive way of administering transgene constructs. Keratinocytes are interesting targets for transfection from a safety point of view, because they show high cell turnover and no need for exogenous controls, as the transgene will only be expressed for the short period of the turnover time. Thus, transfection of keratinocytes holds promise for future treatments of skin diseases. However, the skin barrier function involves challenges to penetration, electrical field distribution, and electrode design (60).

In any case, our study provides the first experimental evidence to our knowledge that targeting angiogenesis by non-viral somatic gene therapy is a promising approach for future treatments of psoriasis and, possibly, other inflammatory disorders.

\section{Methods}

Plasmid preparation. The plasmids $p V A X 1$ (Invitrogen), $p V A X-R D D, p V A X-$ $R F P$, and $P V A X-R D D-R F P$ (Supplemental Figure $1 \mathrm{~A}$ and ref. 33) were used. $p V A X-R F P$ contained a PRFP-Monomer-N1 derived from the tetrameric Discosoma RFP (Clontech). RFP and/or RDD were cloned into the $p G A 4$ (ampR) site of $p V A X 1$. The plasmids were amplified in One Shot TOP10F' E. coli Competent Cells (Invitrogen) and prepared using the EndoFree Plasmid Mega Kit or Giga Kit (Qiagen) or the NucleoBond XtraMaxi Kit (Macherey-Nagel). Plasmid concentration and quality were controlled by spectrophotometry and gel electrophoresis and confirmed by sequencing.

Cells and functional in vitro assays. HUVECs (Cambrex) or CPAE endothelial cells (33) were cultured in Endothelial Cell Growth Medium (PromoCell). Human fibroblasts were cultured in MEM, and murine LL/2 cells (LGC Standards) were cultured in RPMI1640. The Nucleofector NHDF Kit (Amaxa) was used for fibroblast transfections, and HiPerFect (Qiagen) was used for LL/2 cells. Transfection efficiencies were determined by FACS.
HUVEC migratory activity was assessed for up to 29 hours in a standardized scratch-wound assay in 6-well plates, using conditioned medium from different fibroblast transfectants.

Mouse models. Experiments using human skin were approved by the Danish National Committee on Biomedical Research Ethics and informed consent was obtained from the patients. Animal experiments were approved by the governmental authorities (Regierung von Unterfranken or Danish Experimental Animal Inspectorate). Mice were housed under SPF conditions.

Mice with epidermal expression of latent human TGF- $\beta 1$ (K5.TGF- $\beta 1$ ) (39) were genotyped by PCR. All experiments were performed with offspring from wild-type females and transgenic males, and wild-type littermates served as controls. Transgenic and wild-type mice were used at 4-8 weeks of age. All mice were monitored in a blinded and standardized manner. For xenotransplantation, psoriasis patients without systemic treatment or phototherapy for 2 months and without topical treatment for at least 14 days were biopsied using a keratome $(0.2 \mathrm{~mm}$; 4 biopsies of involved psoriatic skin from 4 patients [for the active psoriasis model] and 4 biopsies of noninvolved skin from 4 patients [for the inductive model]). Mice were anesthetized by intraperitoneal injection with $100 \mathrm{mg} / \mathrm{kg}$ ketamine (ParkeDavis) and $20 \mathrm{mg} / \mathrm{kg}$ xylazine (Bayer) in $0.5 \mathrm{ml}$ PBS. Skin pieces were transplanted onto the backs of Prkdscid mice (Taconic), and the wounds were closed using Histoacryl (TissueSeal). To induce psoriasis in nonlesional xenografts, $10^{7}$ autologous PBMCs, activated by $20 \mathrm{U} / \mathrm{ml} \mathrm{IL-2} \mathrm{and} 1 \mu \mathrm{g} / \mathrm{ml}$ SEB (Sigma-Aldrich), were injected intraperitoneally after 14 days.

Intramuscular DNA electrotransfer. Gene therapy was performed in 6- to 12 -week-old K5.TGF- $\beta 1$ transgenic mice and in Prkdcsid mice on day 12 after transplantation of nonlesional skin ( 2 days before PBMC injection) or on day 14 after transplantation of involved psoriatic skin. The mice were anesthetized, and $50 \mu \mathrm{g}$ plasmid DNA in $30 \mu \mathrm{l}$ PBS was injected into each tibialis cranialis muscle. Plate electrodes $(4 \mathrm{~mm})$ and a specially modified Cliniporator (IGEA) were used to apply 1 high-voltage pulse $(700 \mathrm{~V} / \mathrm{cm}$, $100 \mu \mathrm{s})$ and 8 low-voltage pulses $(100 \mathrm{~V} / \mathrm{cm}, 50 \mathrm{~ms})$.

Persistence of the transgene was determined in various tissues (including untreated and treated muscles as well as the gonads) using quantitative RT-PCR (level of quantification, 100 plasmid copies) at various times for more than 4 months after gene electrotransfer.

Western blot analysis. To detect secreted protein within the serum of treated mice, $150 \mu \mathrm{g}$ total serum was loaded in each lane in a $12 \%$ polyacrylamide gel with $1 \mathrm{X}$ MOPS. The gel was blotted using the dry iBlot system (Invitrogen). Membranes were blocked in 5\% skimmed milk, washed in TBS, and incubated with rabbit polyclonal antibody against RFP (AB34771; Abcam). The signals were visualized using an enhanced chemiluminescence Western blotting detection system according to the manufacturer's instructions (Amersham, GE Healthcare).

Histology and immunohistochemistry. Paraffin-embedded tissues were stained using H\&E according to standard protocols. For immunohistochemistry of murine tissues, cryostat-cut sections $(4 \mu \mathrm{m})$ were stained as described previously (59). For immunohistochemistry of human tissue, $4-\mu \mathrm{m}$ paraffinembedded sections were stained. Antibodies against the following antigens were used: mCD31 (clone MEC13.3; BD Biosciences), mCD51 (RMV-7; BD Biosciences), mCD49e (HMa5; BD Biosciences), RFP (AB34771; Abcam), hANGPT1 (HPA018816; Sigma-Aldrich), hCD1a (M3571; Dako) hCD3 (UCHT1; Dako), hCD31 (JC70A; Dako), hCD68 (M0876; Dako), hFLT1 (HPA011740; Sigma-Aldrich), hHIF1A (HPA001275; Sigma-Aldrich), hKi67 (MIB-1; Dako), hMac-1 (HPA002274; Sigma-Aldrich), haSMA (1A4; Dako), and hVEGFA (M7273; Dako). Furthermore, Bandeirea simplicifolia-Iagglutinin (BS-1-lectin; Sigma-Aldrich), staining vascular endothelium in many species except human, was used (72). In negative controls, primary antibodies were replaced with appropriate control antibodies. As a positive control, a colon adenocarcinoma was used for the Ki67 stainings, normal 
human and murine skin samples were used for the BS-1-stainings, and a multiblock of liver, kidney, and tonsil were used for the other stainings. Samples were analyzed in a blinded fashion using light and fluorescence stereomicroscopy (Leica or Zeiss). Morphometric analyses to quantitate cutaneous vascularization were performed using ImageJ freeware (http:// rsbweb.nih.gov/ij) as described previously $(73,74)$. The epidermal thickness was measured at 10 randomly chosen sites in each sample (LAS EZ1.6.0, Leica), and averages of the measurements were calculated. Keratinocyte proliferation was determined by counting $\mathrm{Ki} 67^{+}$cells per mm epidermis.

Flow cytometry. Antigen expression was determined using antibodies against the following antigens: CD49e (SAM1; Beckmann-Coulter), CD51 (13C2; Chemikon), and CD51/CD61 (LM609; Chemikon). Cells were analyzed using a FACSCanto II and the DIVA software (BD Biosciences).

$R T$-PCR. Expression of RDD-encoding mRNA was analyzed using semiquantitative RT-PCR. Total RNA was extracted using the E.Z.N.A. RNA Kit (Omega). Thereafter, cDNA was generated using the First Strand cDNA Synthesis Kit (Fermentas) and an oligo(dT) primer (Fermentas). For amplification, Sawady-Taq (PeqLab) and sequence-specific primers (forward, 5'-GCGCCTTGGTGGTGAAAAAC-3'; reverse, 5' - AGTCATCCAGGAAGCCA-3') were used. PCR was performed in a Mastercycler (Eppendorf) as follows: 5 minutes at $94^{\circ} \mathrm{C}$, followed by 30 cycles of 30 seconds at $94^{\circ} \mathrm{C}, 30$ seconds at $60^{\circ} \mathrm{C}$, and 5 minutes at $72^{\circ} \mathrm{C}$.

In vivo blood flow. The Vevo770 Imaging System, equipped with a RMV708 Scanhead and a 3D motor (VisualSonics), was used for high-resolution Doppler ultrasound in 4 areas in each mouse in a standardized fashion (Supplemental Figure 4).
Statistics. Statistical differences were determined by the $\chi^{2}$ test or Student's $t$ test, both 2 -tailed. $P$ values of $<0.05$ (CI 95\%) were considered significant. Data are displayed as mean \pm SD.

\section{Acknowledgments}

We thank M. Bæksted, K. Zachmann, J. Pedersen, A. Bennemann, D. Glahn, M.R. Ramm, M.B. Løvendorf, J. Eriksen, M. Fregil, and B. Hertz for excellent technical assistance; M. Bæksted for help with animal experiments and animal care; and J. Gehl and P.H. Møller for guidance with electrotransfer technology. K5.TGF $\beta 1$ transgenic mice were provided y X.J. Wang (University of Colorado, Denver, Colorado, USA). This work was supported by a collaborative research grant from the European Union to L.M. Mir, V. TrochonJoseph, R. Cadossi, L. Skov, and M.P. Schön (ANGIOSKIN; LSH2003-512127), by a research grant from the Copenhagen County Research Foundation to L. Skov, and by a Rudolf Virchow Award from the Deutsche Forschungsgemeinschaft to M.P. Schön.

Received for publication September 29, 2009, and accepted in revised form October 20, 2010.

Address correspondence to: Michael P. Schön, Department of Dermatology, Venereology, and Allergology, Georg August University, Von-Siebold-Str. 3, 37075 Göttingen, Germany. Phone: 49.551.39.6401; Fax: 49.551.39.6841; E-mail: michael.schoen@ med.uni-goettingen.de.
1. Griffiths CE, Barker JN. Pathogenesis and clinical features of psoriasis. Lancet. 2007;370(9583):263-271.

2. Lowes MA, Bowcock AM, Krueger JG. Pathogenesis and therapy of psoriasis. Nature. 2007; 445(7130):866-873.

3. Schön MP, Boehncke WH. Psoriasis. N Engl J Med. 2005;352(18):1899-1912

4. Schön MP. Psoriasis in the limelight: the remarkable career of an old skin disease. Clin Dermatol. 2007; 25(6):501-503.

5. Bowcock AM, Krueger JG. Getting under the skin: the immunogenetics of psoriasis. Nat Rev Immunol. 2005;5(9):699-711.

6. Liu Y, Krueger JG, Bowcock AM. Psoriasis: genetic associations and immune system changes. Genes Immun. 2007;8(1):1-12.

7. Nickoloff BJ, Xin H, Nestle FO, Qin JZ. The cytokine and chemokine network in psoriasis. Clin Dermatol. 2007;25(6):568-573

8. Boniface K, Blom B, Liu YJ, de Waal Malefyt R. From interleukin-23 to T-helper 17 cells: human T-helper cell differentiation revisited. Immunol Rev. 2008; 226:132-146.

9. Gottlieb AB. Psoriasis: emerging therapeutic strategies. Nat Rev Drug Discov. 2005;4(1):19-34.

10. Leonardi CL, et al. Efficacy and safety of ustekinum$a b$, a human interleukin-12/23 monoclonal antibody, in patients with psoriasis:76-week results from a randomised, double-blind, placebo-controlled trial (PHOENIX 1). Lancet. 2008;371(9625):1665-1674.

11. Menter A, Griffiths CE. Current and future management of psoriasis. Lancet. 2007;370(9583):272-284.

12. Papp KA, et al. Efficacy and safety of ustekinumab, a human interleukin-12/23 monoclonal antibody, in patients with psoriasis:52-week results from a randomised, double-blind, placebo-controlled trial (PHOENIX 2). Lancet. 2008;371(9625):1675-1684.

13. Detmar M, et al. Overexpression of vascular permeability factor/vascular endothelial growth factor and its receptors in psoriasis. J Exp Med. 1994; 180(3):1141-1146.

14. Elias PM, et al. Epidermal vascular endothelial growth factor production is required for perme- ability barrier homeostasis, dermal angiogenesis, and the development of epidermal hyperplasia: implications for the pathogenesis of psoriasis. Am J Pathol. 2008;173(3):689-699.

15. Henno A, et al. Altered expression of angiogenesis and lymphangiogenesis markers in the uninvolved skin of plaque-type psoriasis. BrJ Dermatol. 2009;160(3):581-590.

16. Costa C, Incio J, Soares R. Angiogenesis and chronic inflammation: cause or consequence? Angiogenesis. 2007;10(3):149-166.

17. Halin C, Detmar M. Inflammation, angiogenesis, and lymphangiogenesis. Methods Enzymol. 2008;445:1-25.

18. Rosenberger C, et al. Upregulation of hypoxiainducible factors in normal and psoriatic skin. J Invest Dermatol. 2007;127(10):2445-2452.

19. Simonetti $O$, et al. VEGF is likely a key factor in the link between inflammation and angiogenesis in psoriasis: results of an immunohistochemical study. Int J Immunopathol Pharmacol. 2006;19(4):751-760.

20. Teige I, Hvid H, Svensson L, Kvist PH, Kemp K. Regulatory $\mathrm{T}$ cells control VEGF-dependent skin inflammation. J Invest Dermatol. 2009;129(6):1437-1445.

21. Young HS, Summers AM, Bhushan M, Brenchley PE, Griffiths CE. Single-nucleotide polymorphisms of vascular endothelial growth factor in psoriasis of early onset. I Invest Dermatol. 2004;122(1):209-215.

22. Campanati A, et al. Angiogenesis in psoriatic skin and its modification after administration of etanercept: videocapillaroscopic, histological and immunohistochemical evaluation. Int J Immunopathol Pharmacol. 2009;22(2):371-377.

23. Cañete JD, et al. Antiangiogenic effects of antitumor necrosis factor alpha therapy with infliximab in psoriatic arthritis. Arthritis Rheum. 2004; 50(5):1636-1641

24. Goedkoop AY, et al. Deactivation of endothelium and reduction in angiogenesis in psoriatic skin and synovium by low dose infliximab therapy in combination with stable methotrexate therapy: a prospective single-centre study. Arthritis Res Ther. 2004; 6(4):R326-R334.

25. Markham T, et al. Resolution of endothelial acti- vation and down-regulation of Tie 2 receptor in psoriatic skin after infliximab therapy. J Am Acad Dermatol. 2006;54(6):1003-1012.

26. Heidenreich R, Röcken M, Ghoreschi K. Angiogenesis: the new potential target for the therapy of psoriasis? Drug News Perspect. 2008;21(2):97-105.

27. Saraceno R, Di Stefani A, Giunta A, Chimenti S. Recent patents and new strategies in the treatment of psoriasis. Recent Pat Antiinfect Drug Discov. 2006;1(3):353-364.

28. Nisato RE, Tille JC, Jonczyk A, Goodman SL, Pepper MS. AlphaV beta3 and alphaV beta5 integrin antagonists inhibit angiogenesis in vitro. Angiogenesis. 2003;6(2):105-119.

29. Petitclerc E, et al. New functions for non-collagenous domains of human collagen type IV. Novel integrin ligands inhibiting angiogenesis and tumor growth in vivo. J Biol Chem. 2000;275(11):8051-8061.

30. Rehn M, et al. Interaction of endostatin with integrins implicated in angiogenesis. Proc Natl Acad Sci US A. 2001;98(3):1024-1029.

31. Krätzschmar J, Lum L, Blobel CP. Metargidin, a membrane-anchored metalloprotease-disintegrin protein with an RGD integrin binding sequence. J Biol Chem. 1996;271(9):4593-4596.

32. Zhang XP, Kamata T, Yokoyama K, PuzonMcLaughlin W, Takada Y. Specific interaction of the recombinant disintegrin-like domain of MDC15 (metargidin, ADAM-15) with integrin alphaVbeta3. J Biol Chem. 1998;273(13):7345-7350.

33. Trochon-Joseph V, et al. Evidence of antiangiogenic and antimetastatic activities of the recombinant disintegrin domain of metargidin. Cancer Res. 2004;64(6):2062-2069.

34. Villemejane J, Mir LM. Physical methods of nucleic acid transfer: general concepts and applications. $\mathrm{Br}$ JPharmacol. 2009;157(2):207-219.

35. Heller LC, Ugen K, Heller R. Electroporation for targeted gene transfer. Expert Opin Drug Deliv. 2005; 2(2):255-268

36. Mir LM, et al. High-efficiency gene transfer into skeletal muscle mediated by electric pulses. Proc Natl Acad Sci U S A. 1999;96(8):4262-4267. 
37. Mir LM, Bureau MF, Rangara R, Schwartz B, Scherman $\mathrm{D}$. Long-term high level in vivo gene expression after electric pulse-mediated gene transfer into skeletal muscle. C R Acad Sci III. 1998;321(11):893-899.

38. Wrone-Smith T, Nickoloff BJ. Dermal injection of immunocytes induces psoriasis. J Clin Invest. 1996;98(8):1878-1887.

39. Li AG, Wang D, Feng XH, Wang XJ. Latent TGFbeta1 overexpression in keratinocytes results in a severe psoriasis-like skin disorder. EMBO J. 2004; 23(8):1770-1781.

40. Schön MP. Animal models of psoriasis: a critical appraisal. Exp Dermatol. 2008;17(8):703-712.

41. Primakoff P, Myles DG. The ADAM gene family: surface proteins with adhesion and protease activity. Trends Genet. 2000;16(2):83-87.

42. André FM, et al. Efficiency of high- and low-voltage pulse combinations for gene electrotransfer in muscle, liver, tumor, and skin. Hum Gene Ther. 2008;19(11):1261-1271.

43. Hojman P, Zibert JR, Gissel H, Eriksen J, Gehl J. Gene expression profiles in skeletal muscle after gene electrotransfer. BMC Mol Biol. 2007;8:56.

44. Nickoloff BJ. Characterization of lymphocytedependent angiogenesis using a SCID mouse: Human skin model of psoriasis. J Investig Dermatol Symp Proc. 2000;5(1):67-73.

45. Boehncke WH, Sterry W, Hainzl A, Scheffold W, Kaufmann R. Psoriasiform architecture of murine epidermis overlying human psoriatic dermis transplanted onto SCID mice. Arch Dermatol Res. 1994;286(6):325-330.

46. Creamer D, Allen MH, Sousa A, Poston R, Barker $\mathrm{JN}$. Localization of endothelial proliferation and microvascular expansion in active plaque psoriasis. Br J Dermatol. 1997;136(6):859-865.

47. Folkman J. Angiogenesis in psoriasis: therapeutic implications. J Invest Dermatol. 1972;59(1):40-43.

48. Folkman J. Angiogenesis in cancer, vascular, rheumatoid and other disease. Nat Med. 1995;1(1):27-31.

49. Kuroda K, Sapadin A, Shoji T, Fleischmajer R, Lebwohl M. Altered expression of angiopoietins and Tie2 endothelium receptor in psoriasis. J Invest Dermatol. 2001;116(5):713-720

50. Creamer D, Sullivan D, Bicknell R, Barker J. Angio- genesis in psoriasis. Angiogenesis. 2002;5(4):231-236.

51. Halin $\mathrm{C}$, et al. Inhibition of chronic and acute skin inflammation by treatment with a vascular endothelial growth factor receptor tyrosine kinase inhibitor. Am J Pathol. 2008;173(1):265-277.

52. Heidenreich R, Röcken M, Ghoreschi K. Angiogenesis drives psoriasis pathogenesis. Int J Exp Pathol. 2009;90(3):232-248.

53. Huegel R, et al. Novel anti-inflammatory properties of the angiogenisis inhibitor vasostatin. J Invest Dermatol. 2007;127(1):65-74.

54. Velasco $\mathrm{P}$, et al. The angiogenesis inhibitor thrombospondin- 1 inhibits acute cutaneous hypersensitivity reactions. J Invest Dermatol. 2009;129(8):2022-2030.

55. Akman A, Yilmaz E, Mutlu H, Ozdogan M. Complete remission of psoriasis following bevacizumab therapy for colon cancer. Clin Exp Dermatol. 2008; 34(2):202-204.

56. Detmar M, et al. Increased microvascular density and enhanced leukocyte rolling and adhesion in the skin of VEGF transgenic mice. JInvest Dermatol. 1998; 111(1):1-6

57. Xia YP, Li B, Hylton D, Detmar M, Yancopoulos GD, Rudge JS. Transgenic delivery of VEGF to mouse skin leads to an inflammatory phenotype resembling human psoriasis. Blood. 2003;102(1):161-168.

58 . Voskas D, et al. A cyclosporine-sensitive psoriasislike disease produced in Tie2 transgenic mice. Am J Pathol. 2005;166(3):843-855.

59. Schön MP, Detmar M, Parker CM. Murine psoriasis-like disorder induced by naive CD4+ T cells. Nat Med. 1997;3(2):183-188.

60. Heller LC, Jaroszeski MJ, Coppola D, McCray AN, Hickey J, Heller R. Optimization of cutaneous electrically mediated plasmid DNA delivery using novel electrode. Gene Ther. 2007;14(3):275-280.

61. Creamer D, Allen M, Sousa A, Poston R, Barker J. Altered vascular endothelium integrin expression in psoriasis. Am J Pathol. 1995;147(6):1661-1667.

62. Eto K, Puzon-McLaughlin W, Sheppard D, SeharaFujisawa A, Zhang XP, Takada Y. RGD-independent binding of integrin alpha9beta1 to the ADAM-12 and -15 disintegrin do-mains mediates cell-cell interaction. J Biol Chem. 2000;275(45):34922-34930.

63. Nath D, et al. Interaction of metargidin (ADAM-
15) with alphavbeta 3 and alpha5beta 1 integrins on different haemopoietic cells. J Cell Sci. 1999; 112(pt 4):579-587.

64. Charrier-Hisamuddin L, Laboisse CL, Merlin D. ADAM-15: a metalloprotease that mediates inflammation. FASEB J. 2008;22(3):641-653.

65. Daud AI, et al. Phase I trial of interleukin-12 plasmid electroporation in patients with metastatic melanoma. J Clin Oncol. 2008;26(36):5896-5903.

66. Bloquel $\mathrm{C}$, et al. Intra-articular electrotransfer of plasmid encoding soluble TNF receptor variants in normal and arthritic mice. J Gene Med. 2007;9(11):986-993.

67. Bessis N, GarciaCozar FJ, Boissier MC. Immune responses to gene therapy vectors: Influences on vector function and effector mechanism. Gene Ther. 2004;11(suppl 1):S10-S17.

68. Gossen M, Bujard H. Tight control of gene expression in mammalian cells by tetracyclineresponsive promoters. Proc Natl Acad Sci U S A. 1992;89(12):5547-5551

69. Toniatti C, Bujard H, Cortese R, Ciliberto G. Gene therapy progress and prospects: transcription regulatory systems. Gene Ther. 2004;11(8):649-657.

70. Lin MT, Wang F, Uitto J, Yoon K. Differential expression of tissue-specific promoters by gene gun. Br J Dermatol. 2001;144(1):34-39.

71. Gaelle V, et al. Skin-specific promoters for genetic immunisation by DNA electroporation. Vaccine. 2009;27(32):4272-4277.

72. Young PP, Hofling AA, Sands MS. VEGF increases engraftment of bone marrow-derived endothelial progenitor cells (EPCs) into vasculature of newborn murine recipients. Proc Natl Acad Sci U S A. 2002; 99(18):11951-11956

73. Amschler K, Schön MP, Pletz N, Wallbrecht K, Erpenbeck L, Schön M. NF-kappaB inhibition through proteasome inhibition or IKKbeta blockade increases the susceptibility of melanoma cells to cytostatic treatment through distinct pathways. J Invest Dermatol. 2010;130(4):1073-1086.

74. Michaelis $\mathrm{K}$, et al. Modulating T cell functions does not alleviate chronic inflammatory skin lesions in K5.TGFbeta1 transgenic mice. Exp Dermatol. 2010; 19(5):406-415. 